\title{
Visualisation and Immersion Dome Experience for Inspired Participation
}

\author{
Anna P. Gawlikowska ${ }^{* 1}$, Marcello Marini ${ }^{2}$, Ndoana Chokani ${ }^{3}$, Reza S. Abhari ${ }^{4}$ \\ ${ }^{1}$ Department of Mechanical and Process Engineering, Laboratory for Energy Conversion, ETH Zürich, \\ Sonneggstrasse 3, ML J33, Zürich, Switzerland \\ e-mail: annaga@ethz.ch \\ ${ }^{2}$ Department of Mechanical and Process Engineering, Laboratory for Energy Conversion, ETH Zürich, \\ Sonneggstrasse 3, ML J33, Zürich, Switzerland \\ e-mail: marini@lec.mavt.ethz.ch \\ ${ }^{3}$ Department of Mechanical and Process Engineering, Laboratory for Energy Conversion, ETH Zürich, \\ Sonneggstrasse 3, ML J33, Zürich, Switzerland \\ e-mail: chokani@lec.mavt.ethz.ch \\ ${ }^{4}$ Department of Mechanical and Process Engineering, Laboratory for Energy Conversion, ETH Zürich, \\ Sonneggstrasse 3, ML J33, Zürich, Switzerland \\ e-mail: abhari@lec.mavt.ethz.ch
}

Cite as: Gawlikowska, A. P., Marini, M., Chokani, N., Abhari, R. S., Visualisation and Immersion Dome Experience for Inspired Participation, J. sustain. dev. energy water environ. syst., 6(1), pp 67-77, 2018, DOI: http://dx.doi.org/10.13044/j.sdewes.d5.0165

\section{ABSTRACT}

Public protests, which lead to increased administrative and permission procedures, are amongst the most important obstacles in development of wind energy projects. The community's fears of visual and acoustic impacts of new power plants are commonly recognized as the weakest aspects of public acceptance. To address these issues Visualisation Dome has been designed to better communicate the economic, political, spatial, ecological and social benefits of wind power plants and the associated risks to local communities. The approach combines the experimental and simulation method. The integrated analysis software tool, which allows assessing the impacts of planed wind power plants underpins their 360-degree video and audio simulations. The Visualisation Dome demonstration resulted in $57 \%$ of the interviewed participants improving their opinion of wind power following the experience. Visualisation Dome's novel approach for improving procedural justice of wind energy projects development forms innovative, interactive and streamlined processes, and enables constructive participation of audiences.

\section{KEYWORDS}

Wind energy, Community acceptance, Participation, Visualisation, Auralisation, Interactive planning, Modelling.

\section{INTRODUCTION}

Psychological barriers to Renewable Energy Sources (RES) development is one of the major causes of limited RES potential in the densely populated European Union. Lack of information and well-defined participation strategies are preventing sustained

\footnotetext{
* Corresponding author
} 
acceptance at the local level and, in turn, the support of public administration [1]. This results in local protests, which can delay or even block projects' development, thereby having a negative impact on political support for RES, increasing associated risks, and expected Internal Rates of Return (IRR) on investments [2]. To address these barriers the Visualisation Dome has been prepared to enhance RES community acceptance.

Existing research addresses benefits and obstacles perceived by local residents in respect of RES, as well as in the planning process involved, for example the role of participation [3] or landscape impacts of wind turbines. For example, research provides evidence that participative processes as well as guidelines for authorities and planners reduce the transaction costs of projects and increase their success [4-6]. Poorly established legal procedures can negatively influence local acceptance, and the absence of action protocols or guidelines can also be difficult for administrative offices and development companies [7]. Additionally, acceptance is negatively influenced by safety measures, such as obstruction markings and lightings of offshore turbines [8]. Lack of community-centric approach [9], with no active community-engagement as a part of planning processes [10], evokes opposition, as communities feel excluded from decisions affecting them $[11,12]$. Additionally, failure to establish a relationship of trust between project operators, decision makers and local residents is known to have substantial adverse effects on the implementation of renewable energy projects [13]. Furthermore, uncertainties about the impact of wind turbines and transmission lines on human health foster opposition [14]. In summary, the existing research on community acceptance offers a better understanding of acceptance factors, though it is limited due to its predominantly post-factum design and passive role of communities [15]. As a result broader shifts toward participatory processes can be observed, and they are starting to become a norm of land use change decision-making [9]. So far acceptance interventions have not been systematically developed in an interdisciplinary manner, and community acceptance has not been included in systematic RES potential analyses.

The Visualisation Dome is designed to enhance community acceptance of RES based on the implementation of best practices using modern communication solutions, and participatory design. In order to prove this hypothesis, a prototype of the Visualisation Dome has been built and tested. The majority of participants of the public showing in September 2014 in Lublin stated that their opinion of wind power plants improved following their immersion experience in the Dome, with only $5 \%$ of the audience stating the opposite [16].

\section{Challenges and improvement potentials of wind energy acceptance}

If one appreciates wind energy, why not have it in the backyard? Well, "In theory there is no difference between theory and practice. In practice there is" [17]. There is a difference between general support for wind power, and support for a particular project, which requires understanding, participation, consideration of costs and benefits, and sometimes addressing questions about larger social benefit. Once a project is to be constructed in close proximity of a settlement, it is relatively easy to communicate potential negative results of such project construction - which tend to be also more attractive for the press. It is also relatively easy to awaken local population's emotions of being marginalised and victimised by larger and potent forces, standing behind the project's construction. It is more complicated to address the possible positive impacts, which requires more sophisticated tools and communication, addressing economics, population self-esteem, as well as providing realistic visualisations of future impacts. The last point can also act as a materialisation of the future development within the imaginations of inhabitants, which can lower fears towards real future developments. The protests against wind energy gather more media interest, leading to the higher visibility of negative opinions. This phenomenon can be partially addressed by well-prepared 
communication material. Interesting content can be based on ambient advertisement and small architecture experiences. Such an approach can also capture the public's interest, leading to higher participation of people with neutral and positive approaches towards wind energy. This can assure more equality in the points of view represented and a wider range of participants in the decision making process [18]. Improved community participation is beneficial for the decision legitimization [19]. To fully address the community perception issue, the notion of fairness needs to be achieved. It is linked to the concept of justice, in particular procedural and distributive justice. Procedural justice, which is addressed by the Visualisation Dome, refers to a fair decision making process that gives all relevant stakeholders an opportunity to participate [20], and be provided with trustworthy information from trusted sources. In contrast, distributive justice refers to fair distribution of costs and benefits amongst project stakeholders.

\section{RENEWABLE ENERGY COMMUNITY IMMERSION DOME}

Participatory Visualisation Dome (Figure 1) has been designed as a tool for local institutions to address social fears and myths about the visual and acoustic impact of RES. Previous research and practical experience provide clear evidence that the impact of RES on the landscape is an important acceptance factor [21]. Additionally to RES, potential negative impact on the landscape of powerlines is also perceived [22]. Consequently, it is believed that the well designed, modern and interactive Dome, which allows communities to participate in the planning process through interactive visualisation programme based on EnerPol software [23], will result in increased public acceptance, and media outreach, leading to better political support for RES. The solution includes several steps, including:

- Wind energy feasibility study using EnerPol software;

- Production and logistics of visualisation and auralisation dome;

- Projection experience.

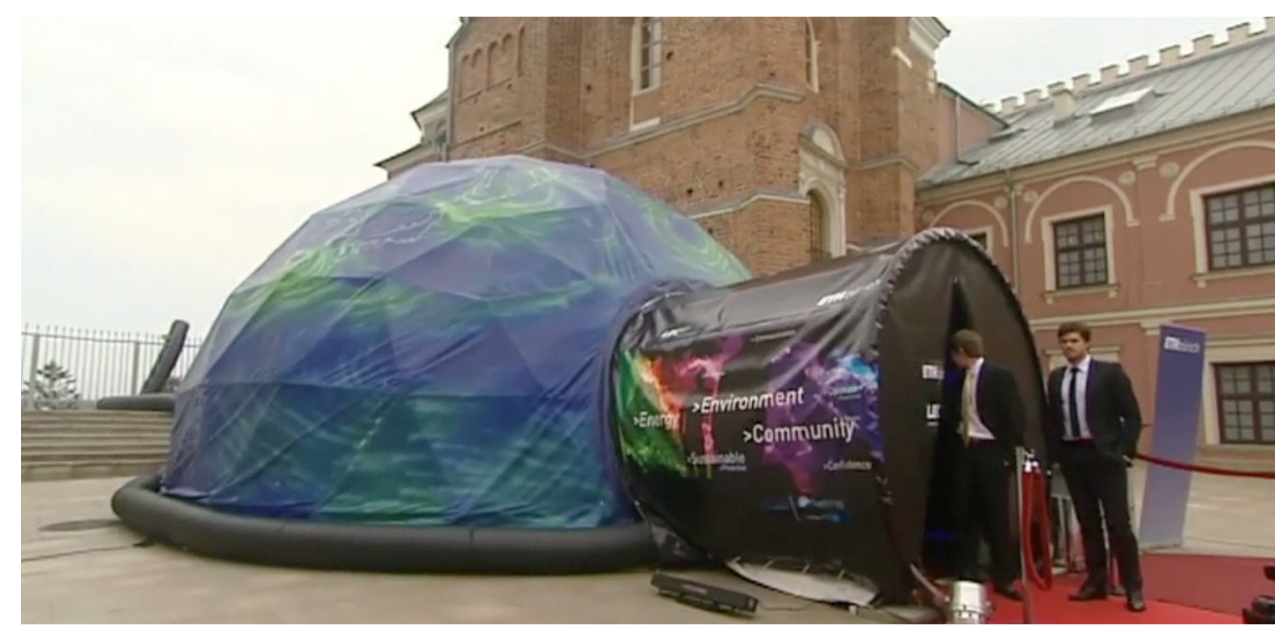

Figure 1. Visualisation dome exterior

\section{EnerPol software}

Analyses of potential RES projects are conducted with EnerPol. EnerPol is a system-wide, bottom-to-top framework for the assessment of power generation mix, electricity transmission infrastructure, market performance and the impact of policy. The EnerPol framework includes a high-resolution database, with more than 200 anthropological, geographical, climatic, regulatory and financial variables; this framework therefore allows for physical modelling of power generation and electricity transmission [24]. Due to the scientific approach the choice of locations with high wind 
energy potential development has a neutrality characteristic, which is an important aspect in the acceptance process.

To define the eligible areas for the installation of the wind parks a series of optimization steps in terms of economic impact is performed.

The integration of the Visualisation Dome into the EnerPol framework is novel, as the state of the art GIS mapping in the prior EnerPol framework mainly takes into account technological, weather and geographic information, whereas the Dome brings in social and psychological aspects, apart from outcomes from participatory GIS initiatives [25].

\section{Visualisation Dome}

Chosen development areas are visualised and auralised in order to allow for the first-person experience. A Visualisation Dome with a diameter of $9.5 \mathrm{~m}$ has already been developed at ETH Zürich (Figure 1). It is easy to transport and quick to mount with little manpower and low maintenance costs. The main feature of the Dome is its provision of an immersive experience. Participants can select the point of view they want to see from a $360^{\circ}$ photorealistic projection of the required facilities and their impact on the current landscape. The spectators will be free to move inside, observing the surroundings and experiencing the energy production of the future. The experience will be enhanced by realistic audio reproduction of the facility sounds, calculated to accurately represent the specific area, superimposing real-time ambient sounds.

To achieve such an immersive experience that is easy to transport, the Visualization Dome is equipped with 8 projectors connected to a single high power video server, capable of full Dome projection. The surround audio system is composed of a 5.1 audio system hidden behind the projection membrane. Real time visualization capabilities are obtained through rendering form software supported by a game-engine framework. To allow mobility, the structure of the tent is composed of a light geodesic steel frame covered by a pitch-black membrane. A seamless internal projection surface is obtained by the depressurization of an internally placed second membrane.

\section{Projection experience}

The purpose of the Dome is to allow the audience to express their opinions about the proposed wind turbine locations, allowing the local authorities as well as developers to take public opinion into account. The solution utilises digital spatial technologies, in particular Geographic Information Systems (GIS), which are often used for problem solving and information dissemination, especially by community organisations during the wind projects public consultation process [26-29]. In the Visualisation Dome, experience is enriched through:

- Directional sound projection is obtained by speakers located behind the projection membrane and controlled by the game-engine. It calculates the amount and type of sound that would be heard from the visualised point of view;

- Ability of interaction is allowed through a large touch screen showing an interactive interface. The user can freely chose the point of view from a situation map and decide what wind turbines layout to view, by choosing between different number of turbines, model and size. In addition to the layout options, the user is able to select the day of the year and time of the day, visualizing the landscape with appropriate light and weather conditions obtained from high resolution weather simulations;

- Surrounding visualization is provided by 8 projectors placed in the centre of the Dome and connected to a video server specifically designed for the structure (Figure 2);

- Real-time supportive information, such as produced power, electricity generated and economic indicators such as IRR and Tax reductions are calculated by the 
system following the user interaction with chosen visualized layouts and locations. Such information is shown on the Dome entrance door and on the interactive touch screen;

- The spectators are given a specific questionnaire to be filled out at the end of the 15 minute presentation in order for the researchers to understand the participants' reactions. The questions are related to both general experience of the surveyed person and relative acceptance, and to the interactive experience inside the Dome. The questionnaire is focused on positive and negative influences of the Visualization Dome experience in relation to wind turbines acceptance.

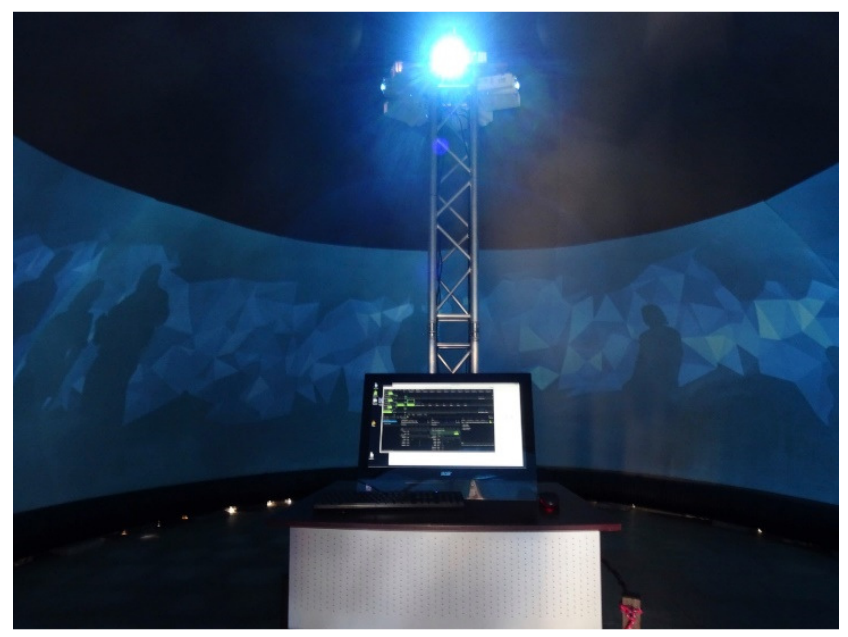

Figure 2. Visualisation Dome interior

\section{BACKGROUND - PSYCHOLOGICAL ASPECTS}

Understanding the local conditions is a prerequisite for developing successful communication and participation strategies aimed to promote renewable energies. An energy project will change the landscape to a lower or higher extent, depending on the investment scale and context. Innovations are connected with uncertainties and risks, opportunities and benefits, as well as feared negative consequences. Whereas some people are open to change and ambiguous situations, others mistrust and reject any transformation. These possible reactions need to be addressed to promote innovation acceptance. In the case of renewable energy projects the needs and motivations of different groups have to be matched by the final chosen solutions, as well as by the accompanying communication and procedural strategies. To provide reliable and valid communication tools, impact of these tools on the local acceptance has to be assessed.

\section{Professional communication package}

Research on community acceptance provides evidence [30] that even a single persuasive information leaflet addressing particular fears of citizens, identified through surveys, could increase community acceptance, significantly, by about $13 \%$. One crucial challenge is to promote the local residents' involvement. This can be achieved, for example, by informing residents about experiences of comparable communities and statements of other citizens. The Visualisation Dome offers an outstanding possibility to encourage involvement, provide information and allow for participation.

\section{Fostering community participation}

Community participation "improves the chances of reaching consensus, makes the decision making process more transparent, the outcome more valuable and the leading actors involved more accountable" [31]. Consequently it has been recognised as one of 
the major aspects of local acceptance [32-34], and therefore a special focus is put on community participation within the Visualisation Dome project. The Dome's physical test-bed, utilizing a virtual full immersion environment, has been set up to allow individuals in a community to interact and possibly adjust the layout of renewable energy projects and provide feedback. Most importantly, through such a setup, local residents will be offered the opportunity to participate in the actual planning of the energy project. More specifically, they will be invited to participate in the final design and location of the project and will be provided options based on the economic and system optimization analyses of EnerPol. This setup will assure a democratic process, and meet recommendations for community participation [35]. Furthermore, people's participation in the decision making process tends to mean that they are more likely to accept the results, as it legitimizes the program and actors involved [36]. It is a part of procedural fairness, which should assure dignity and self-sufficiency to the individual [37].

\section{Addressing identity}

Any renewable energy project, planned in a certain neighbourhood, has an effect on local identity, and therefore personal identity of individuals [3]. As identity is connected with strong emotions, it should be carefully addressed. This includes understanding characteristics and meanings associated with certain places by individuals and social groups as they affect expectations, priorities and solutions chosen by the community. It should also mean addressing these issues in the planning process [38]. Assigning meaning to the neighbourhood "can serve as a powerful way for community organizations to enhance the legitimacy" [38], it should therefore be addressed in the wind project acceptance process. According to the place attachment research (e.g. $[39,40])$ this procedure seems to be crucial in creating local acceptance for projects that influence the landscape. Moreover, being able to address the issue of spatial identity impacts the agency and authority of institutions involved in the decision making process [41-44]. Therefore, the design of the Visualization Dome is based on the hypothesis that through an interactive tool for local institutions, perceptions regarding proposed renewable energy production technology can be altered and the targeted population can assess the real advantages and impacts of the proposed project. As the visualizations are provided within the photorealistic context, people are able to recognize details of the space they are identified with. The realism of visualization and participation will help people to feel more considered within the planning process, potentially leading to higher acceptance levels.

\section{RESULTS}

Major concerns related to development of RES for the Polish population are the lack of transparency of developers, impact on landscape and noise. The Visualization Dome was built as a tool to address these concerns through better organisation and facilitation of the wind energy project participative planning process. This tool was further tested in Lublin, with the scope of realistically presenting wind turbines inside the landscape, allowing collection of data on influence on acceptance by usage of immersive audio visual simulations. The device received very positive consent from the local population, also benefiting in terms of increased understanding and acceptance of wind turbines.

\section{Background: Wind energy in Poland}

Participation in community decision-making is a form of civil society activity, which is often country specific. In the European Union, the Netherlands, with a well-developed civil society, represents one side of the spectrum, and Poland, with a much less developed civil society, the other end [45]. In the Netherlands, $55 \%$ of citizens belonged to a civil 
society organization in 2007, about $44 \%$ have volunteered in the last 10 years, and $72 \%$ participated in mayoral elections [46]. On the other hand, Poland occupies the last position in the EU in terms of social trust in the political establishment [47], which translates into community participation levels. In 2011 only $14.8 \%$ of Poles belonged to social organization [48], 5.5\% of adults had volunteered in a twelve-month period measured across 2008/2009 [48], and as little as 47.4\% participated in the 2014 local elections [49].

That status of Polish civil society does not positively influence social support for the country's transition to a post-carbon economy. Even though renewable energies enjoy medium to high acceptance levels (Figure 3), currently the sector is in decline. 84\% of the population stated that their acceptance of wind energy would be positively influenced through information regarding real impacts of the technology, and $71 \%$ see a need for social consultation [50]. At the same time, the major concerns relate to the possible negative impact on the surroundings (33.1\%) and noise levels (72\%) [51].

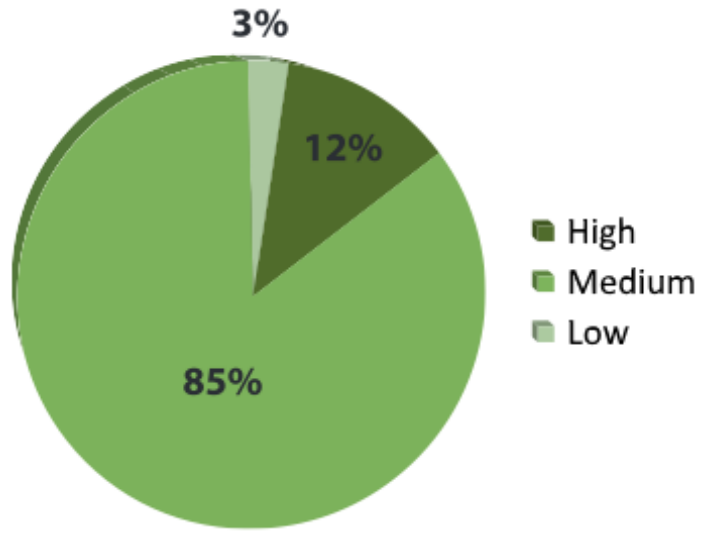

Figure 3. Acceptance level of RES in Poland

\section{Prototyping and first public showing}

To address acceptance and participation issues, the Visualization Dome prototype was built and further tested in Poland [51]. The prototype was built mostly integrating the market standard equipment. Calibration and testing inside the Dome have been conducted at the ETH.

The structure was presented for the first time in Lublin (Poland), during the final conference for the project "NEO: New Energy for Lubelskie" [17], to present renewable energy options for the region. The Dome was installed for one week inside the Castle of Lublin, an important tourist point for the city, which allowed a large number of people to participate.

\section{Results}

During its one-week presentation time, the Dome was presented to up to 100 people from different age groups. Being a sample of local tourists, their distribution generally matched the local population demographics.

In terms of appreciation, the audience reacted very positively to the Visualization Dome. 57\% stated that their opinion about Wind Energy positively changed after the presentation, even if they considered the show to have been too long. The Visualization Dome can be considered a very attractive possibility to capture the attention of the local population of the areas selected for wind energy development, opening new possibilities of dialogue and information to increase acceptance of this technology. In addition, the survey revealed that up to $92 \%$ of the investigated population would like to show the Visualization Dome in their community. 
The Visualization Dome also allowed for the collection of interesting data about the population of the Lubelskie Region's appreciation of and relationship with wind energy. This data enables the continued evaluation of the impact of wind energy on the population.

\section{CONCLUSIONS}

The Visualisation Dome has been designed and built as a tool to better organises and facilitate the wind energy project participative planning process. The Dome has been setup in alliance with participation facilitation methods:

- Through participatory setup it provides an appropriate organizational structure for participants to express their interests;

- Through well designed information on visual and acoustic impacts of various solutions, as well as their concrete economic benefits, it increases citizens' competence;

- As it includes predefined processes and is mobile, meaning it can be transported to the effected communities, it assures a time-efficient solution;

- Through unusual design and experience creation it provides entertaining activity, making it interesting for the local population and media;

- Through the presentation setup, as well as seating design it provides a non-confrontational community environment;

- As it is attractive for all age groups, it provides an entertaining activity, and it allows for a more neutral group setup by catering to majority of the population;

- The game-like control design of the Dome provides a user-friendly interface;

- The Dome builds the affected community's self-esteem by high tech solutions and highly localized content - addressing identity issues;

- As it shows the future designs in a realistic and encompassing manner, both visually and with audio experiences of various projects, it provides an answer to the need of tranquilizing fears about the unknown future.

In practice, the Dome has been designed to provide people an experience of renewable energy projects within their familiar landscapes, and offer them a dedicated space to discuss the related issues. But the Dome has to be understood as a potential part of a larger acceptance process. In the first field test, $57 \%$ of the 100 visitors to the Visualisation Dome in Lublin stated that it had "improved their opinion about wind energy". To achieve long-term positive outcomes in terms of local acceptance of wind energy, the multi-staged engagement process needs to be established and carefully implemented.

\section{REFERENCES}

1. Huijts, N. M. A., Molin, E. J. E. and Steg, L., Psychological Factors influencing Sustainable Energy Technology Acceptance: A Review-based Comprehensive Framework, Renewable and Sustainable Energy Reviews, Vol. 16, No. 1, pp 525-531, 2012, https://doi.org/10.1016/j.rser.2011.08.018

2. Hall, N. L. and Jeanneret, T., Social Licence to Operate, Corp. Commun.: Int. J., Vol. 20, No. 2, pp 213-227, 2015, https://doi.org/10.1108/CCIJ-01-2014-0005

3. Gawlikowska, A. P., Energy and Space, Managing Social Acceptance of Change (in Polish), Poznań Polytechnic Architecture Department Press, Poznań, Poland, 2014.

4. Bruns, E. and Ohlhorst, D., Wind Power Generation in Germany A Transdisciplinary View on the Innovation Biography, Journal of Transdisciplinary Environmental Studies, Vol. 10, No. 1, pp 45-67, 2011. 
5. McLaren, L., Wind Energy planning in England, Wales and Denmark: Factors influencing Project Success, Energy Policy, Vol. 35, No. 4, pp 2648-2660, 2007, https://doi.org/10.1016/j.enpol.2006.10.008

6. Friedl, C. and Reichl, J., Realizing Energy Infrastructure Projects - A Qualitative Empirical analysis of Local Practices to Address Social Acceptance, Energy Policy, Vol. 89, pp 184-193, 2016, https://doi.org/10.1016/j.enpol.2015.11.027

7. Moragues-Faus, A. M. and Ortiz-Miranda, D., Local Mobilisation against Wind Farm developments in Spanish Rural Areas: New Actors in the Regulation Arena, Energy Policy, Vol. 38, No. 8, pp 4232-4240, 2010, https://doi.org/10.1016/j.enpol.2010.03.053

8. Pohl, J., Hübner G. and Mohs, A., Acceptance and Stress Effects of Aircraft Obstruction Markings of Wind Turbines, Energy Policy, Vol. 50, pp 592-600, 2012, https://doi.org/10.1016/j.enpol.2012.07.062

9. Colvin, M., Witt, G. B. and Lacey, J., How Wind became a Four-letter Word: Lessons for Community engagement from a Wind Energy Conflict Inking Island, Australia, Energy Policy, Vol. 98, pp 483-494 and 266-276, 2016, https://doi.org/10.1016/j.enpol.2016.09.022

10. Fast, S., Mabee, W., Baxter, J., Christidis, T., Driver, L., Hill, S., McMurtry, J. J. and Tomkow, M., Lessons learned from Ontario Wind Energy Disputes, Nat. Energy, Vol. 1, 2016, https://doi.org/10.1038/nenergy.2015.28

11. Moffat, K., Lacey, J., Zhang, A. and Leipold, S., The Social Licence to Operate: A Critical Review, Forestry, Vol. 89, No. 5, pp 477-488, 2015, http://dx.doi.org/10.1093/forestry/cpv044

12. Ross, H., Baldwin, C. and Carter, R. W., Subtle Implications: Public Participation versus Community engagement in Environmental Decision-making, Australas. J. Environ. Manag., Vol. 23, No. 2, pp 123-129, 2016, https://doi.org/10.1080/14486563.2016.1194588

13. Wolsink, M., Planning of Renewables Schemes: Deliberative and Fair Decision-making on Landscape Issues instead of Reproachful Accusations of Non-cooperation, Energy Policy, Vol. 35, No. 5, pp 2692-2704, 2007, https://doi.org/10.1016/j.enpol.2006.12.002

14. Mroczek, B., Man and Environment, Awareness and Social Acceptance (in Polish), Continuo, Wroclaw, Poland, 2011.

15. IAP2, Quality Assurance Standard for Community and Stakeholder Engagement, International Association for Public Participation, 2015, http://www.iap2.org. au/documents/item/391, [Accessed: 01-March-2017]

16. Abhari, R. S., Chokani, N., Gawlikowska, A., Ioannou, A., Singh, A., Subramanian, B., Vinklers, J. and Zendehbad, Z., Final Report - Systematic Planning for Development of Wind Energy in Lubelskie, Zürich, Switzerland, 2014.

17. "Yogi" Berra, L. P., Quote.

18. Beirle, T. C. and Cayford, J., Democracy in Practice: Public Participation in Environmental Decisions, Resources for the Future, Washington D. C., USA, 6 p, 2002.

19. Petts, J. and Leach, B., Evaluating Methods for Public Participation: Literature Review, R\&D Technical Report: E2-030, Environment Agency, Bristol, UK, 2000.

20. Wüstenhagen, R., Wolsink, M. and Bürer, M. J., Social acceptance of Renewable Energy Innovation: An Introduction to the Concept, Energy Policy, Vol. 35, No. 5, pp 2683-2691, 2007, https://doi.org/10.1016/j.enpol.2006.12.001

21. Möller, B., Spatial analyses of emerging and fading Wind Energy Landscapes in Denmark, Land use Policy, Vol. 27, No. 2, pp 233-241, 2010, https://doi.org/10.1016/j.landusepol.2009.06.001

22. Devine-Wright, P. and Batel, S., Explaining Public Preferences for High Voltage Power Lines: An Empirical Study of Perceived Fit in a Rural Landscape, Land use Policy, Vol. 31, pp 640-649, 2013, https://doi.org/10.1016/j.landusepol.2012.09.011 
23. Singh, A., Eser, P., Chokani, N. and Abhari, R., Improved modelling of demand and Generation in High Resolution Simulations of Interconnected Power Systems, $12^{\text {th }}$ International Conference on the European Energy Market (EEM), Piscataway, NJ: IEEE, 2015, https://doi.org/10.1109/EEM.2015.7216689

24. Eser, P., Singh, A., Chokani, N. and Abhari, R., High Resolution Simulations of Increased Renewable Penetration on Central European Transmission Grid, IEEE Power \& Energy Society General Meeting, Piscataway, NJ: IEEE, 2015.

25. Elwood, S., Beyond Cooptation or Resistance: Urban Spatial Politics, Community Organizations, and GIS-Based Spatial Narratives, Annals of the Association of American Geographers, Vol. 96, No. 2, pp 323-341, Blackwell Publishing, Oxford OX4 2DQ, UK, 2006.

26. Elwood, S., GIS and Collaborative Urban Governance: Understanding their Implications for Community Action and Power, Urban Geography, Vol. 22, No. 8, pp 737-759, 2002, https://doi.org/10.1080/02723638.2001.11501633

27. Harris, T. and Weiner, D., Empowerment, Marginalization, and Community-oriented GIS, Cartography and Geographic Information Systems, Vol. 25, No. 2, pp 67-76, 1998, https://doi.org/10.1559/152304098782594580

28. Crampton, J., Maps as Social Constructions: Power, Communication and Visualization, Progress in Human Geography, Vol. 25, No. 2, pp 235-352, 2001, https://doi.org/10.1191/030913201678580494

29. Ghose, R., Use of Information Technology for Community Empowerment: Transforming Geographic Information System into Community Information Systems, Transactions in GIS, Vol. 5, No. 2, pp 141-163, 2001, https://doi.org/10.1111/1467-9671.00073

30. Hübner, G. and Pohl, J. Acceptance of Offshore Wind Energy (in German), Research Report in Preparation, Martin-Luther-Universität Halle-Wittenberg, Halle, Germany, 2014.

31. Higgs, G., Berry, R., Kidner, D. and Langford, M., Using IT approaches to promote Public Participation in Renewable Energy Planning: Prospects and Challenges, Land use Policy, Vol. 25, No. 4, pp 596-607, 2008, https://doi.org/10.1016/j.landusepol.2007.12.001

32. Cowell, R., Bristow, G. and Munday, M., Acceptance, Acceptability and Environmental Justice: The Role of Community Benefits in Wind Energy development, Journal of Environmental Planning and Management, Vol. 54, No. 4, pp 539-557, 2011, https://doi.org/10.1080/09640568.2010.521047

33. Devine-Wright, P., From Backyards to Places: Public engagement and the emplacement of Renewable Energy Technologies, Renewable Energy and the Public: From NIMBY to Participation, pp 57-70, London: Earthscan, UK, 2011.

34. Toke, D., Breukers, S. and Wolsink, M., Wind Power Deployment Outcomes: How can we Account for the Differences?, Renewable and Sustainable Energy Reviews, Vol. 12, No. 4, pp 1129-1147, 2008, https://doi.org/10.1016/j.rser.2006.10.021

35. Citizen Participation in Community Development, Ohio State University Fact Sheet, www.ohioline.osu.edu/cd-fact/1700.html, [Accessed: 01-March-2017]

36. Heberlein, T. A., Principles of Public Involvement, Department of Rural Sociology, Madison: University of Wisconsin, Madison, Wisconsin, USA, 1976.

37. Cahn, E. S. and Camper, J., Citizen Participation in Urban development (Speigel, H. B. C., ed.), N\&L Institute for Applied Behavioral Science, Washington D. C., USA, 1968.

38. Elwood, S., Beyond Cooptation or Resistance: Urban Spatial Politics, Community Organizations, and GIS-Based Spatial Narratives, Annals of the Association of American Geographers, Vol. 96, No. 2, pp 323-341, Blackwell Publishing, Oxford, UK, 2006. 
39. Cotton, M. and Devine-Wright, P., Making Electricity Networks 'Visible': Industry Actor Constructions of 'Publics' and Public engagement in Infrastructure Planning, Public Understanding of Science, Vol. 21, pp 17-35, 2012, https://doi.org/10.1177/0963662510362658

40. Devine-Wright, P., Place Attachment and Public Acceptance of Renewable Energy: A Tidal Energy Case Study, Journal of Environmental Psychology, Vol. 31, No. 4, pp 336-343, 2011, https://doi.org/10.1016/j.jenvp.2011.07.001

41. Fraser, J., Lepofsky, J., Kick, E. and Williams, J., The Construction of the Local and the Limits of Contemporary Community building in the United States, Urban Affairs Review, Vol. 38, No. 3, pp 417-445, 2003, https://doi.org/10.1177/1078087402238808

42. Martin, D., Constructing Place: Cultural Hegemonies and Media Images of an Inner City Neighborhood, Urban Geography, Vol. 21, No. 5, pp 380-405, 2000, https://doi.org/10.2747/0272-3638.21.5.380

43. McCann, E., Framing Space and Time in the City: Urban Policy and the Politics of Spatial and Temporal Scale, Journal of Urban Affairs, Vol. 25, No. 2, pp 159-178, 2003, https://doi.org/10.1111/1467-9906.t01-1-00004

44. Wilson, D. and Grammenos, D., Spatiality and Urban Redevelopment Movements, Urban Geography, Vol. 21, No. 4, pp 361-370, 2000, https://doi.org/10.2747/0272-3638.21.4.361

45. Czułno, P., Civil Society in the Netherlands and Poland - Learning from the Dutch, Science Quarterly of the Center for Political Analysis of the Warsaw University, No. V, pp 223-224, 2013.

46. Bijl, R., The Social State of the Netherlands, The Netherlands Institute for Social Research, SCP, The Hague, pp 227-228, 2010.

47. Wenzel, M. and Kubik, J., Civil Society in Poland, Case study, The Logic of Civil Society in New Democracies: East Asia and East Europe Conference, Taipei, Taiwan, 2009, http://www.cbos.pl/PL/wydarzenia/04_konferencja/Civil\%20society\%20in\% 20Poland.pdf, [Accessed: 01-March-2017]

48. Czapiński, J. and Panek, T., Social Diagnosis 2011, Objective and Subjective Quality of Life in Poland, Contemporary Economics, Quarterly of University of Finance and Management in Warsaw, Vol. 5, No. 3, 2011, http://ce.vizja.pl/en/download-pdf/volume/5/issue/3/id/260, [Accessed: 01-March-2017]

49. Announcement of the National Electoral Commission of 23 November 2014 on the Consolidated Results of the Elections of Vogts, Mayors and City Presidents in the Country, conducted on 16 November 2014 (in Polish), http://pkw.gov.pl, [Accessed: 25-November-2014]

50. Mroczek, B., (Red), Acceptance of Adult Poles for Wind Power Sources and other Renewable Energy Sources (in Polish), Department of Public Health of Pomeranian Medical University in Szczecin, Polish Wind Energy Association, Szczecin, Poland, 2011.

51. Marini, M., Visualization Dome: Improving Social Acceptance of Renewable Energy, M.Sc. Thesis, Zürich, Switzerland, 2014. 